\title{
CAPILLARY PRESSURE - SATURATION RELATIONSHIPS FOR GAS SHALE'S MEASURED USING A WATER ACTIVITY METER
}

\author{
B. Donnelly ${ }^{1}$, E. Perfect ${ }^{1}$, L.D. McKay $^{1}$, P.J. Lemiszki ${ }^{2}$, V.H. DiStefano ${ }^{3,4}$, \\ L.M. Anovitz ${ }^{4}$ J. McFarlane ${ }^{5}$, R.E. Hale ${ }^{6}$, and C.- L. Cheng ${ }^{7}$
}

${ }^{1}$ Department of Earth and Planetary Sciences, University of Tennessee - Knoxville, Knoxville, TN 37996, USA

${ }^{2}$ Tennessee Division of Geology, Department of Environment and Conservation, Knoxville, TN 37921, USA

${ }^{3}$ Bredesen Center for Interdisciplinary Research and Graduate Education, University of Tennessee - Knoxville, TN 37996, USA

${ }^{4}$ Chemical Sciences Division, Oak Ridge National Laboratory, Oak Ridge, TN 37831, USA

${ }^{5}$ Energy and Transportation Science Division, Oak Ridge National Laboratory, Oak Ridge, TN 37831, USA

${ }^{6}$ Reactor and Nuclear Systems Division, Oak Ridge National Laboratory, Oak Ridge, TN 37831, USA

${ }^{7}$ Department of Environmental and Earth Sciences; Department of Civil Engineering, University of Texas - Rio Grande Valley, Edinburg, TX 78539, USA

* Corresponding author: e-mail: eperfect@utk.edu, phone: (865) 974-6017 


\begin{abstract}
Hydraulic fracturing of gas shale formations involves pumping a large volume of fracking fluid into a hydrocarbon reservoir to fracture the rock and thus increase its permeability. The majority of the fracking fluid introduced is never recovered and the fate of this lost fluid, often called "leak off," has become the source of much debate. Information on the capillary pressure - saturation relationship for each wetting phase is needed to simulate leak off using numerical reservoir models. The petroleum industry commonly employs air - water capillary pressure - saturation curves to predict these relationships for mixed wet reservoirs. Traditional methods of measuring this curve are unsuitable for gas shale's due to high capillary pressures associated with the small pores present. A possible alternative method is the water activity meter which is used widely in the soil sciences for such measurements. However, its application to lithified material has been limited. This study utilized a water activity meter to measure air water capillary pressures (ranging from 1.3 - 219.6 MPa) at several water saturation levels in both the wetting and drying directions. Water contents were measured gravimetrically. Seven types of gas producing shale with different porosities $(2.5-13.6 \%)$ and total organic carbon contents $(0.4-13.5 \%)$ were investigated. Nonlinear regression was used to fit the resulting capillary pressure - water saturation data pairs for each shale type to the Brooks and Corey equation. Data for six of the seven shale types investigated were successfully fitted (median $\mathrm{R}^{2}$ $=0.93$ ), indicating this may be a viable method for parameterizing capillary pressure - saturation relationships for inclusion in numerical reservoir models. As expected, the different shale types had statistically different Brooks and Corey parameters. However, there were no significant differences between the Brooks and Corey parameters for the wetting and drying measurements, suggesting that hysteresis may not need to be taken into account in leak off simulations.
\end{abstract}




\section{Keywords}

Water activity meter, capillary pressure, volumetric water content, porosity, shale, Brooks and Corey

\section{Acknowledgements}

The authors wish to thank Consol Energy Inc. (Pittsburgh, PA) for providing the Chattanooga and Marcellus shale samples. E. Perfect acknowledges funding from David E. Jackson of BDY Environmental LLC, Nashville, TN through a Faculty Achievement Award. 


\section{Introduction}

Hydraulic fracturing, or "fracking," is a practice employed by the petroleum industry in the exploitation of hydrocarbon reservoirs previously discounted due to inadequate porosity, low permeability, or high cost of development. It is largely responsible for the rapid growth in shale gas production. The "fracking" process involves pumping large volumes of water containing chemical additives and suspended solids (proppants) at high pressure into the subsurface in order to fracture rock around the well bore and thus increase the permeability of the reservoir rock (Myers, 2012). This increased permeability allows for the extraction of hydrocarbons that would otherwise not be recoverable. However, the majority of the fluid used during the fracking process is never recovered and its whereabouts have become the source of much debate and study (King, 2012). This lost fluid, often called "leak off," raises concerns from an environmental health perspective as it can potentially contaminate aquifers (Myers, 2012). Leak off can also negatively impact the profitability of a well for two reasons: the fluid cannot be recycled and its presence in the subsurface can effectively block gas flow to the well (Holditch, 1979).

Numerical reservoir models are widely used by the petroleum industry to predict production, improve profitability, and understand potential hazards. To numerically simulate the multiphase flows associated with fracking operations, including leak off, information is needed on the capillary pressure - saturation relationships for the different wetting phases present. Since these can be difficult and time consuming to determine individually, the petroleum industry commonly employs the two-phase air-water capillary pressure - saturation curve to predict these relationships for mixed wet reservoirs (Leverett and Lewis, 1941; Bradford and Leij, 1996).

Capillary pressure, $\mathrm{P}_{c}$, is the pressure difference across the curved interface of two immiscible fluids within a partially-saturated porous medium due to the interfacial tension, $\sigma$, 
between the fluids (Vavra et al., 1992). This difference is related to the properties of the fluids and their interaction with the solid surface (Christoffersen and Whitson, 1995; Newsham et al., 2004; Takahashi and Kovscek, 2010; Roychaudhuri et al., 2011). The Young-Laplace equation defines the relationship between $\mathrm{P}_{\mathrm{c}}$ and $\sigma$ for perfectly cylindrical pores:

$$
\mathrm{P}_{\mathrm{c}}=\frac{2 \sigma \cos \gamma}{\mathrm{r}}
$$

where $\gamma$ is the contact angle between the wetting fluid and the solid surface, and $r$ is the pore radius (Selley, 1985). It can be seen from Eq. (1) that capillary pressure increases as pore size decreases. This relationship is especially important when working with gas shales, as the pore radii of these rocks can be orders of magnitude smaller than pore radii of conventional reservoir rocks, such as sandstones or carbonates (Aguilera, 2014).

For two immiscible fluids in a particular rock type, the degree of wetting fluid saturation depends upon the capillary pressure. For the air-water system, the degree of saturation is the ratio of the water volume to the total pore volume of that material. As the porous medium dries from complete saturation, the water is displaced by air and is contained in pore spaces of decreasing size which results in higher capillary pressures (Brooks and Corey, 1964; Vavra et al., 1992). Conversely, during imbibition, water occupies the smallest pores first before displacing air from larger pores, resulting in a decrease in capillary pressure as the material becomes more saturated (Vavra et al., 1992; Schmitt et al., 1994).

The relationship between capillary pressure and wetting fluid saturation impacts the relative permeability of a material and reflects both the heterogeneity of the pore structure and chemical interactions between the fluid and the solid phase (Purcell, 1949; Shang et al., 1995). It is generally constructed experimentally from paired measurements of capillary pressure and saturation made under quasi-equilibrium conditions (Melrose et al., 1994). Because of hysteresis 
this relationship may differ depending on if the measurements are made during drainage from a saturated state versus wetting up from residual water content. Knowledge of this hysteretic relationship is essential in order to model fluid flow, estimate recovery of oil and gas, predict leak off, and enhance recovery of oil and gas from a well (Li and Horne, 2007; Takahashi and Kovscek, 2010; Dehghanpour et al., 2012; Sakhaee-Pour and Bryant, 2014).

Many equations exist for parameterizing the capillary pressure - saturation relationship (Fredlund and Xing, 1994). One of the earliest and most widely utilized is the Brooks and Corey equation given below (Brooks and Corey, 1964):

$$
\begin{gathered}
\theta_{\mathrm{v}}=\phi\left[0 \leq \mathrm{P}_{\mathrm{c}} \leq \mathrm{P}_{\mathrm{e}}\right] \\
\theta_{\mathrm{v}}=\theta_{\mathrm{r}}+\left(\phi-\theta_{\mathrm{r}}\right)\left(\frac{\mathrm{P}_{\mathrm{e}}}{\mathrm{P}_{\mathrm{c}}}\right)^{\lambda}\left[\mathrm{P}_{\mathrm{c}}>\mathrm{P}_{\mathrm{e}}\right]
\end{gathered}
$$

where $\theta_{\mathrm{v}}$ is the volumetric wetting fluid content, $\theta_{\mathrm{r}}$ is the residual wetting fluid content, $\phi$ is the porosity, $\mathrm{P}_{\mathrm{e}}$ is the entry pressure (i.e., the capillary pressure at which the largest accessible pores drain or fill), and $\lambda$ is the pore size distribution index, which describes the range of pore sizes present. Estimates of the Brooks and Corey parameters (i.e., $\theta_{\mathrm{r}}, \mathrm{P}_{\mathrm{e}}$, and $\lambda$ ) are usually obtained inversely by fitting Eq. (2) to paired measurements of $\mathrm{P}_{\mathrm{c}}$ and $\theta_{\mathrm{v}}$ for a given rock type, with $\phi$ measured independently. Because of hysteresis, fitting Eq. (2) to wetting and drying data can be expected to result in different sets of parameter estimates.

The necessity of accurate capillary pressure - saturation data for modeling petroleum reservoir flow characteristics has been noted in many studies (Slobod et al., 1951; Melrose, 1990; Donaldson et al., 1991; Morrow and Mason, 2001). Such measurements have become more important as the petroleum industry moves to the production of unconventional petroleum 
reservoirs (Clarkson et al., 2011; Josh et al., 2012). However, there is currently a dearth of information on this relationship for gas shales.

Several researchers have investigated spontaneous imbibition (i.e., the rate at which a wetting fluid enters a dry porous medium without the application of any external force) in gas shales in relation to the leak off phenomenon or as a possible means of increased hydrocarbon production (Takahashi and Kovscek, 2010; Wang et al., 2011; Roychaudhuri et al., 2011; Dehghanpour et al., 2012; Gao and $\mathrm{Hu}, 2016$ ). However, we are unaware of any previous efforts to characterize the capillary pressure - saturation relationship of gas shales. This is likely due to their small pore sizes and resulting high capillary pressures which limit the applicability of traditional measurement methods such as porous plates and centrifugation (Fig. 1). As a result, alternative techniques, such as the water activity meter and water vapor desorption, need to be explored to measure the high capillary pressures relevant to gas shales. $।$

The water vapor desorption method of measuring capillary pressure is based on the Kelvin equation (Thomson, 1872; Skinner and Sambles, 1972). This equation describes the relationship between the equilibrium vapor pressure of a material, the surface tension of the liquid, and the radius of curvature at the vapor/liquid interface. Since capillary pressure is also related to surface tension and radius of curvature, the Kelvin equation can be used to express $\mathrm{P}_{\mathrm{c}}$ in terms equilibrium vapor pressure, i.e.

$$
\mathrm{P}_{\mathrm{c}}=\ln \left(\frac{\mathrm{p}}{\mathrm{p}_{0}}\right) \frac{\mathrm{RT}}{\mathrm{V}_{\mathrm{m}}}
$$

where $\mathrm{p}$ is the vapor pressure of water within a porous medium, $\mathrm{p}_{0}$ is the vapor pressure of pure free water at the same temperature, $\mathrm{R}$ is the universal gas constant, $\mathrm{T}$ is temperature in Kelvin, and $\mathrm{V}_{\mathrm{m}}$ is the molar volume of water (Melrose, 1987; Newsham et al., 2004). Assuming there are 
no solutes present in the pore water, Eq. (3) can be used to calculate capillary pressures from measurements of the vapor pressure ratio, $\mathrm{p} / \mathrm{p}_{0}$, or relative humidity.

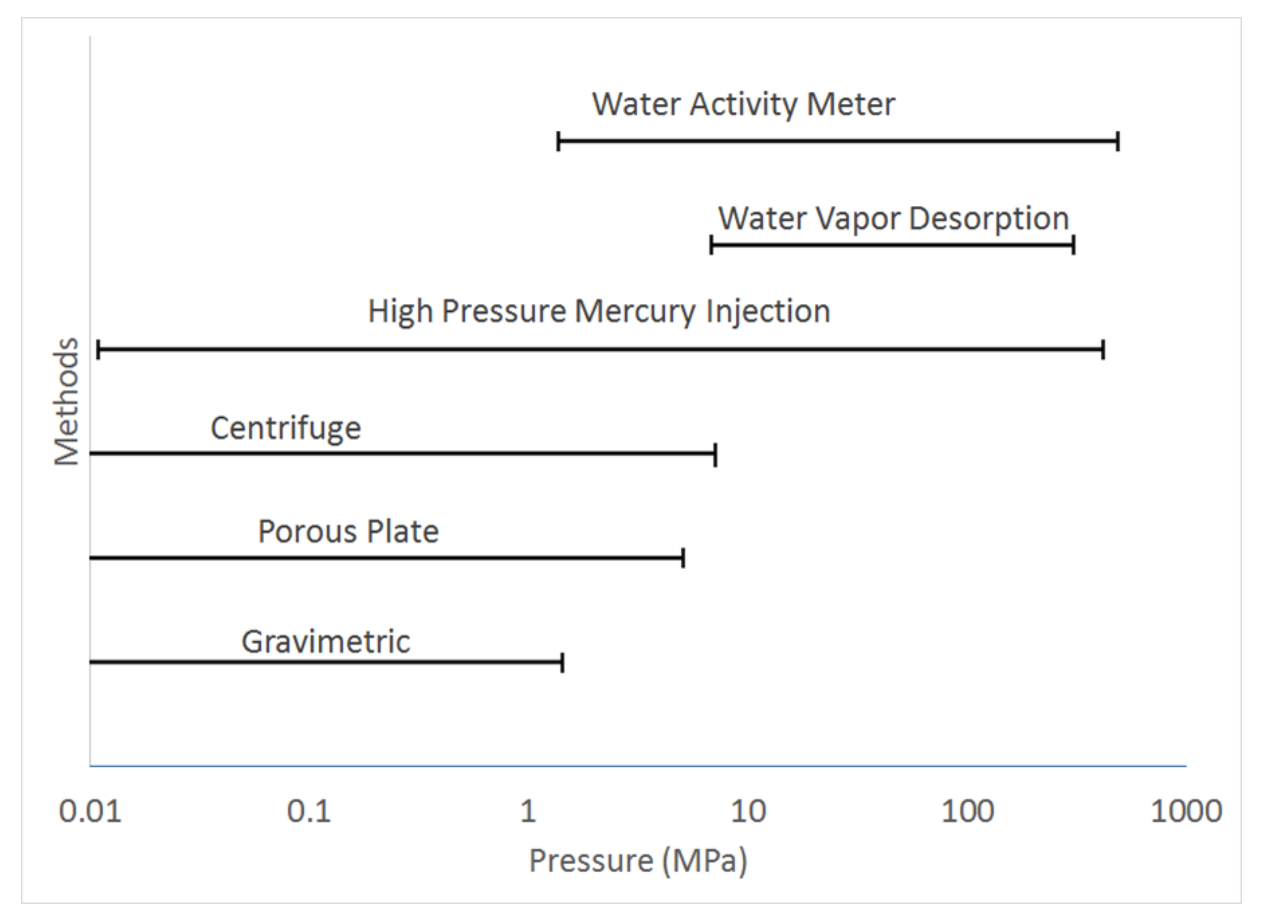

Figure 1. Different methods for measuring capillary pressure - saturation relations in porous media and their approximate capillary pressure ranges. Capillary pressures in conventional reservoirs typically range up to $\sim 3 \mathrm{MPa}$, while those in unconventional reservoirs typically range up to $\sim 500 \mathrm{MPa}$.

Measurements are taken by placing samples in a desiccator with a controlled humidity and weighing the sample periodically until no changes in mass are noted (Chenevert, 1970). At this point, water in the sample is in equilibrium and capillary pressure can be calculated based on the relative humidity within the desiccator using Eq. (3). Water content is calculated based on the mass change between the dry sample and the equilibrium mass of the sample. The relative humidity within the desiccator is then changed in order to perform more paired measurements of water content and capillary pressure (Melrose, 1987). This is typically accomplished through the 
use of various salt solutions which impact the vapor pressure of water and thus the relative humidity within the desiccator (Chenevert, 1970; Melrose, 1987; Newsham et al., 2004).

The water vapor desorption method has been applied to shales to characterize their water activity-saturation relationships, mainly in the development of drilling mud (Chenevert, 1970; Mody and Hale, 1993; Oleas et al., 2010). The theory is that once the water activity of a shale formation at its in-situ saturation is known, the water activity of the drilling fluid can be matched to it in order to combat fluid loss and subsequent swelling (Chenevert, 1970; Mody and Hale, 1993; Zhang et al., 2008). However, none of these studies have noted that water activity can be converted to $\mathrm{P}_{\mathrm{c}}$ for characterizing the capillary pressure - saturation relationship.

Water activity meters measure the relative humidity of air in equilibrium with a sample in a sealed chamber. The activity of water $\left(\mathrm{a}_{\mathrm{w}}\right)$ is then determined using the following relationship (Jarrett et al., 2004):

$$
\mathrm{a}_{\mathrm{w}}=\frac{\mathrm{f}}{\mathrm{f}_{0}} \cong \frac{\mathrm{p}}{\mathrm{p}_{0}}
$$

where $f$ is the fugacity or escaping tendency of water in a porous medium and $f_{0}$ is the fugacity or escaping tendency of pure free water (Chenevert, 1970). Fugacity is closely related to vapor pressure so that $\mathrm{f} / \mathrm{f}_{0}$ can be approximated by $\mathrm{p} / \mathrm{p}_{0}$ (Chenevert, 1970). Based on the relationship between $\mathrm{a}_{\mathrm{w}}$ and p/po in Eq. (4), Eq. (3) can be rewritten as follows (Schmitt et al., 1994):

$$
\mathrm{P}_{\mathrm{c}}=\ln \left(\mathrm{a}_{\mathrm{w}}\right) \frac{\mathrm{RT}}{\mathrm{V}_{\mathrm{m}}}
$$

Once the water activity of the sample is measured, Eq. (5) can then be used to calculate the capillary pressure, assuming no solutes are present in the pore water.

This method is similar to the water vapor desorption method in that the determination of capillary pressure relies on the relationship between the curved surface of a liquid held by 
capillary forces and the vapor pressure ratio under equilibrium conditions. As a result, water activity meters are capable of measuring water held at very high capillary pressures (up to $\sim 450$ MPa). As noted earlier and shown in Fig.1, this is of great importance when characterizing gas shales, especially at low saturation values. In the water activity meter method a measurement is made when the vapor pressure ratio reaches equilibrium, whereas in the vapor desorption method it is made when the sample mass no longer changes with time. As a result, measurements of water activity (and thus $\mathrm{P}_{\mathrm{c}}$ ) can be completed in a matter of hours (Jarrett et al., 2004).

Water activity meters have been used in the soil sciences to measure capillary pressure saturation relationships of various soils (Gee et al., 1992; Perfect et al., 2004; Cancela et al., 2006; Ojeda et al., 2006; Zhuang et al., 2008). In contrast, their use has been quite limited in the study of lithified materials. One study advocated for their use to match the water activity of shale at its in-situ saturation with the water activity of drilling fluids (Jarrett et al., 2004). However, this approach undervalues the utility of the method by limiting its use to a single value of saturation, for the sole purpose of maintaining wellbore stability. To the best of our knowledge, only two studies have previously used the water activity meter method to determine capillary pressures over a range of saturations on lithified materials (Green et al., 1995; Flint, 2003). In both cases, measurements were made on igneous rocks and neither study noted the novelty of the technique or its inherent advantage in the low saturation range typically applicable to shale.

The goal of this study was to test the efficacy of the water activity meter method for determining air-water capillary pressure - saturation relationships of samples from a range of gas shale formations. To pursue this goal, two main objectives must be met. First, the method must be able to collect capillary pressure - saturation data over a wide range of saturations during both wetting and drying. Second, for the measurements to be useful in reservoir simulation, the data 
should be capable of being parameterized using the Brooks and Corey (1964) equations. Since the rocks studied were from a range of gas producing shale units with different porosities, compositions, maturities, and estimates of ultimate recovery, it was hypothesized that the shale types would have different Brooks and Corey (1964) parameters. It was also hypothesized that the Brooks and Corey (1964) parameters for any given shale type would be different for the wetting and drying directions due to hysteresis.

\section{Materials and Methods}

\subsection{Shale Types Investigated}

Several types of shale from oil or gas producing formations within the United States were investigated. An industry partner, Consol Energy Inc. (Pittsburgh, PA), provided core samples of two types of Chattanooga Shale - an organic rich core and an inorganic core both from Tennessee, as well as core samples of Marcellus Shale from two different localities Pennsylvania (PA) and West Virginia (WV). The Chattanooga Shale is a gas producing, bituminous, siliceous, and sulfide shale from the Late Devonian (Glover, 1954; Roen and Kepferle, 1993). The organic Chattanooga Shale core (subsequently referred to as black Chattanooga) was black in color with dark grey inter-bedding, while the inorganic core (referred to as grey Chattanooga) was light grey in color. Both Chattanooga cores contained pyrite grains. The Marcellus Shale is a carbonaceous shale found in Ohio, New York, Pennsylvania, Virginia, and West Virginia (Bruner and Smosna, 2011). It is one of the most prolific gas producing formations in the United States with estimates of recoverable natural gas ranging from 53 to 14,000 billion cubic meters (Stevens and Ruuskraa, 2009). Both cores of Marcellus Shale were dark grey to black in color with lighter grey lenses interspersed throughout. 
Cores of Mancos Shale, Barnett Shale, and Eagle Ford Shale were obtained from outcrops with unknown locations by Kocurek Industries Inc. (Caldwell, TX), a commercial vendor. The Mancos Shale is an interbedded siltstone and shale located in New Mexico, Wyoming, and Utah, from the Late Cretaceous with an estimated 595 billion cubic meters of recoverable gas (McLennan et al., 1983; U.S. Energy Information Administration, 2011). The Mancos samples were grey in color with light grey inter-bedding. The Barnett Shale is a petroliferous and fossiliferous shale located in north Texas and is Mississippian in age (Bruner and Smosna, 2011). As of 2011, the Barnett Shale has estimated recoverable reserves of 1,203 billion cubic meters representing $\sim 6 \%$ of the total shale gas in the United States (U.S. Energy Information Administration, 2011). The Barnett Shale samples were black in color with rare dark grey lenses. Finally, the Eagle Ford Shale is a late Cretaceous, bituminous shale found in south Texas (Mullen, 2010). The Eagle Ford samples obtained for this study were black in color with light grey inter-beds found throughout. The United States Energy Information

Administration (2011) estimates there to be $\sim 588$ billion cubic meters of recoverable natural gas and 3 billion barrels of recoverable oil, making Eagle Ford one of the most prolific shale reservoirs in the country.

\subsection{Sample Preparation and Characterization}

Cores from the different shale types were subsampled to provide material that would fit in the sample cups of the water activity meter (Fig. 2A). The Chattanooga Shale and Marcellus Shale cores were $7.6 \mathrm{~cm}$ and $8.9 \mathrm{~cm}$ in diameter respectively. A rock saw was used to obtain 6 irregularly-shaped samples, $\sim 0.5 \mathrm{~cm}$ thick $\times \sim 2 \mathrm{~cm}$ maximum width, of each of these shale types. The commercially-acquired shale cores were $1.9 \mathrm{~cm}$ in diameter. These cores were 
sectioned with a rock saw into 6 cylindrical samples, $\sim 0.5 \mathrm{~cm}$ length $\times 1.9 \mathrm{~cm}$ diameter, for each shale type. No cutting fluid was used in the operation of the rock saw. The subsamples were wiped with a dry tissue (Chem-Wipe) in order to remove any dust leftover from the cutting process. Leftover material from the cores was retained for matrix density, porosity and total organic carbon measurements.

All the shale samples and leftover material were placed in an oven and dried for 24 hours at $105^{\circ} \mathrm{C}$ in order to remove any in situ water following the protocol established by Ojeda et al. (2006). Individual samples were then weighed in order to determine their oven dry mass, corresponding to zero water content. The volume of the solid phase $\left(\mathrm{V}_{\mathrm{s}}\right)$ was measured on replicate samples of each shale type using a helium gas pycnometer (HumiPyc Model 1, InstruQuest Inc., Coconut Creek, FL) (Oppenheimer et al., 1997). The accuracy of these measurements is $0.01 \%$ according to the HumiPyc user manual. Matrix density was computed from the $V_{s}$ values combined with the oven dry mass measurements. The porosity ( $\left.\phi\right)$ was determined based on the following equation:

$$
\phi=1-\frac{\mathrm{V}_{\mathrm{s}}}{\mathrm{V}_{\mathrm{b}}}
$$

where $\mathrm{V}_{\mathrm{b}}$ is the bulk volume of the sample. The bulk volumes of all of the shale types, except Eagle Ford Shale, were determined with a NextEngine Desktop 3D laser scanner (NextEngine Inc., Santa Monica, CA) following the method described by Rossi et al. (2008). The bulk volumes of the Eagle Ford Shale samples, which were perfectly cylindrical, were determined from length and diameter measurements made using digital calipers. The accuracies of the laser scanner and digital caliper measurements of $\mathrm{V}_{\mathrm{b}}$ are $0.11 \%$ and $0.39 \%$, respectively (Gragg, 2012). Tukey's Studentized Range Test, which compares multiple mean values in conjunction with an Analysis of Variance (ANOVA), was used to test the null hypothesis that there were no 
differences between the different shale types in terms of matrix density and porosity (SAS, 2012).

Approximately 1 gram of oven dry material from each shale type was ground using a mortar and pestle for total organic carbon analysis. This ground material was sent to Ellington and Associates, Inc. (Houston, TX) where total organic carbon content (TOC, weight \%) was measured using standard methods (Mull, 1995; Schumacher, 2002). Briefly, the ground material was first weighed, and then leached using hydrochloric acid. Leached material was combusted with pure oxygen at $2100^{\circ} \mathrm{C}$ and the mass of the resulting carbon dioxide was measured in an infrared detection cell using a LECO C-230 Carbon Analyzer. This mass was then converted to percent carbon based on the pre-combustion mass of the sample. Since there was no replication, the TOC measurements could not be analyzed using ANOVA.

\subsection{Capillary Pressure - Saturation Measurements}

The main wetting and main drying branches of the capillary pressure - saturation curve were measured on each shale type using the water activity method (Ojeda et al., 2006). The main wetting branch was measured first. Immediately following oven drying, subsamples of the shales were placed in individual containers, $\sim 4 \mathrm{~cm}$ in diameter by $1 \mathrm{~cm}$ in height, and sealed (Fig. 2A). They were then allowed to cool to room temperature before being opened and vapor wetted with distilled water using an ultrasonic humidifier (Model 693-12/ 809996, Sunbeam Products Inc., Hattiesburg, MS). Using a modified version of the method described by Ojeda et al. (2006), each subsample was wetted for an interval of 10 seconds. The moistened subsamples were allowed to equilibrate for 24 hours in a dry sealed sample container; this was done to allow water to move into the pore structure of the rock. 


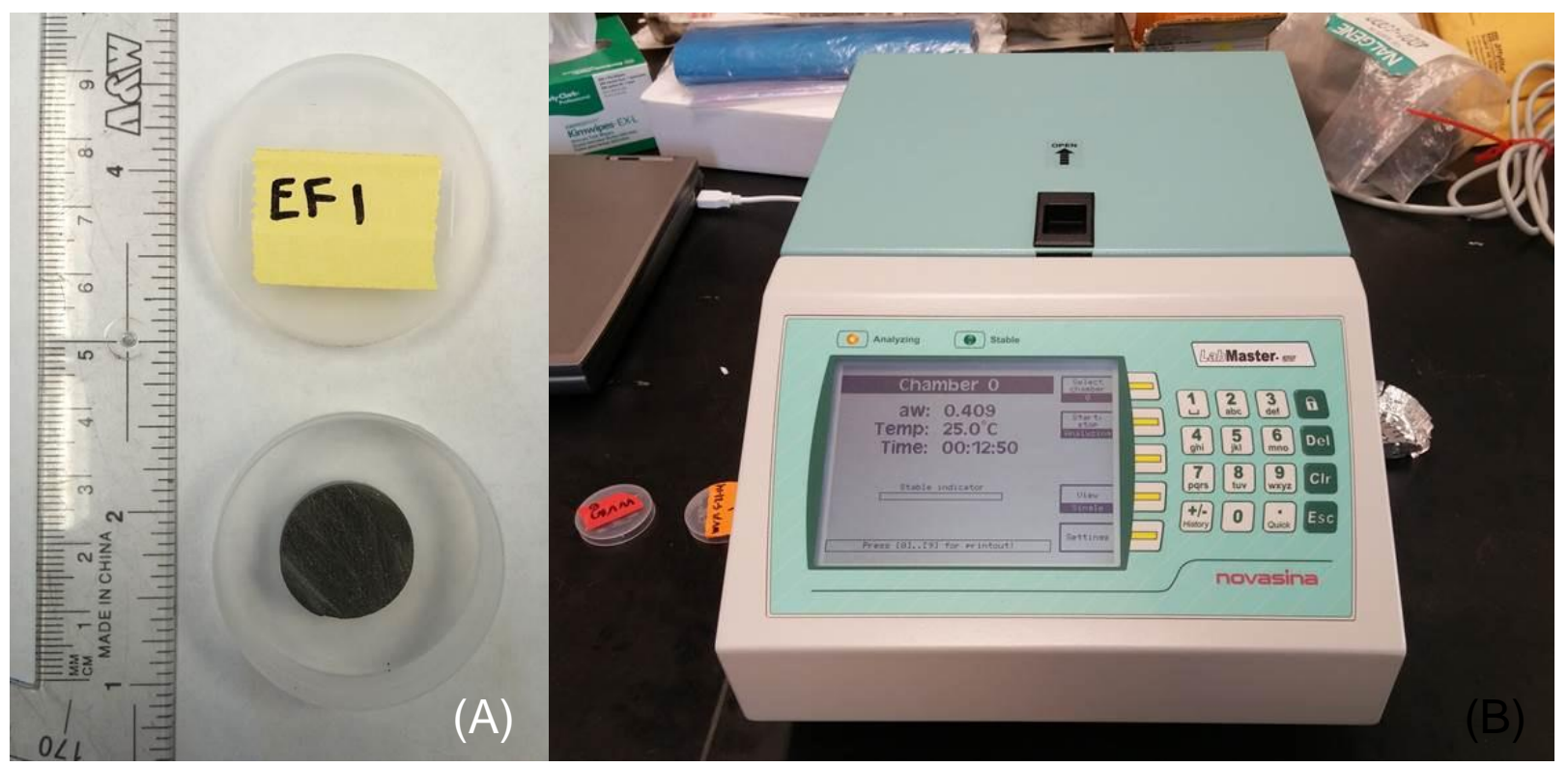

Figure 2. (A) Typical shale subsample (EF1- Eagle Ford \#1) in sample cup (with the lid off) used to measure capillary pressure in (B) the Novasina LabMaster-aw water activity meter.

Water activity $\left(\mathrm{a}_{\mathrm{w}}\right)$ was measured on the vapor-wetted samples using a Novasina LabMaster-aw (Novasina AG, Lachen, Switzerland) (Fig. 2B). This instrument measures the equilibrium relative humidity, or the water activity, of a sample in a sealed chamber using a resistive-electrolytic sensor at a controlled temperature. It contains a primary measurement chamber and a secondary chamber that allows for temperature equilibration. A manufacturer recommended universal, chemical pre-filter was placed between the instrument sensor and the sample chamber in order to prevent the influence of aromatic hydrocarbons, oil vapors, and dust on the measured values of $\mathrm{a}_{\mathrm{w}}$. While the samples equilibrated, the water activity meter was calibrated using six salt solutions, with known $\mathrm{a}_{\mathrm{w}}$ values. After equilibration, one subsample was placed in the water activity meter and analyzed, while another subsample was placed into the secondary chamber. The temperature of the meter was set to $25^{\circ} \mathrm{C}$ and the equilibration time was set to the instrument maximum of 30 minutes. Once water activity was measured the 
subsample was removed, and the subsample in the secondary chamber was placed in the primary chamber for analysis, while another subsample was placed in the secondary chamber.

After all the subsamples of a given shale type had been vapor wetted for 10 seconds, analyzed by the water activity meter and weighed, they were vapor wetted again, this time for 20 seconds. The subsamples were again allowed to equilibrate in a sealed container for 24 hours, analyzed using the water activity meter and weighed. This process was continued with a progressive doubling of the wetting time between measurements; wetting intervals of 40, 80 , 120, 240, and 480 seconds were used, after which the subsamples were submerged in distilled, deionized water for a period of $\sim 2$ weeks in order to achieve near complete saturation after which they were analyzed in the water activity meter and weighed for the last time. After this process was completed for a given shale type, the instrument's calibration was checked again using salt solutions. At no point did the instrument drift out of calibration.

Capillary pressures were calculated from the measured water activity values using Eq. (5). Uncertainty was calculated using the manufacturer's specifications for the water activity meter along with Eq. (5). For water activity values $\geq 0.970$ (or $\geq 4.2 \mathrm{MPa}$ ) the error in measuring capillary pressure was $\pm 1.3 \mathrm{MPa}$. For water activity values $<0.970$ or $(<4.2 \mathrm{MPa})$, the error ranged from 0.4 to $1.0 \mathrm{MPa}$ depending on the magnitude of the measurement; uncertainty was greater at high water activity values (low capillary pressures) than at low water activity values (high capillary pressures).

Immediately after a water activity value was reported the mass of the subsample was recorded using a Mettler-Toledo AG104 analytical balance (Mettler Toledo, LLC, Toledo, OH). The difference between the oven dry mass and the moist mass allowed for the determination of 
the gravimetric water content $\left(\theta_{\mathrm{g}}\right)$. The volumetric water content $\left(\theta_{\mathrm{v}}\right)$ was then calculated using the following expression:

$$
\theta_{\mathrm{v}}=\frac{\theta_{\mathrm{g}} \mathrm{p}_{\mathrm{b}}}{\mathrm{p}_{\mathrm{w}}}
$$

where $p_{\mathrm{w}}$ is the density of water assumed to be $1 \mathrm{~g} \mathrm{~cm}^{-3}$ (with zero error) and $\mathrm{p}_{\mathrm{b}}$ is the dry bulk density calculated from the oven dry mass and $V_{b}$ from the total porosity determination. The accuracy of the scale used to weigh the samples was $\pm 0.0001 \mathrm{~g}$. The error in $\mathrm{p}_{\mathrm{b}}$ was based on the standard deviation of all of the measurements for a given shale type. Uncertainty in volumetric water content was then calculated using standard expressions for the calculation of total error. This uncertainty ranged from \pm 0.001 to $\pm 0.01 \mathrm{~m}^{3} \mathrm{~m}^{-3}$.

The paired measurements of capillary pressure and volumetric water content allowed the main wetting branch of the capillary pressure - saturation relationship to be constructed. The main drying branch of the capillary pressure - saturation relationship was determined in much the same way as the main wetting branch. However, instead of wetting the subsamples, an initially saturated subsample was exposed to air in the laboratory (typically at $24^{\circ} \mathrm{C}$ and $25-35 \%$ relative humidity) for 10 seconds and then allowed to equilibrate for 24 hours in a sealed sample container. After equilibration, capillary pressure and volumetric water content were determined as described for the wetting direction. After all subsamples of a given shale type that had been dried for 10 seconds had been analyzed by the water activity meter and weighed, the partiallydried subsamples were dried for 20 seconds. The subsamples were then allowed to equilibrate for 24 hours in a sealed container before being analyzed in the water activity meter and weighed. This process was repeated with paired measurements of capillary pressure and water content being taken after doubling the drying time between measurements. Drying intervals continued to double until the mass of the sample stabilized. Percent mass loss was calculated from the percent 
difference between the oven dry mass before sample wetting and drying, and the oven dry mass after sample wetting and drying.

\subsection{Parameterization and Statistical Analyses}

The Brooks and Corey (1964) equation, Eq. [2], was fitted separately to data for both the main wetting branch and the main drying branch of the capillary pressure-saturation relationship for each shale type using segmented non-linear regression analysis (SAS, 2012). The measured mean, and in some cases maximum, porosities $(\phi)$ for a given shale type were included as known values, with the $\theta_{\mathrm{r}}, \mathrm{P}_{\mathrm{e}}$, and $\lambda$ parameters treated as unknown values to be estimated. A bounds statement of zero was set for the $\theta_{\mathrm{r}}$ parameter to prohibit the regression from estimating negative residual water contents. As noted previously the uncertainty in the measurement of capillary pressure is high at low values of capillary pressure. As a result of this uncertainty, there is no statistical difference between a measured capillary pressure of $1.3 \mathrm{MPa}$ and $0 \mathrm{MPa}$. To reflect this uncertainty, all capillary pressure measurements whose calculated uncertainties were $\leq 1.3$ MPa were excluded from the regression analyses.

There were 6 subsamples of each shale type for the drying measurements. For the wetting measurements there were 6 subsamples for the Mancos, Eagle Ford, and Barnett Shales and 3 subsamples for the Marcellus (PA and WV) and Chattanooga (grey and black) Shales. The nonlinear regression analyses were performed on the pooled data for all of the subsamples for each wetting / drying regime of a particular shale type. Goodness of fit was assessed using the coefficient of determination $\left(\mathrm{R}^{2}\right)$ between the observed and predicted values. The regression analyses were also checked by examining the residuals for normality using the Shapiro-Wilk test, autocorrelation using the Durbin-Watson test, and homoscedasticity using the Chi-squared test. 
Statistical differences between the estimated Brooks and Corey (1964) parameters were assessed based on the approximate $95 \%$ confidence intervals for the estimated parameters. If the confidence intervals for two estimates of a particular parameter overlapped it was concluded that there was no significant difference between the shale types being compared. These comparisons were only performed on the $\mathrm{P}_{\mathrm{e}}$ and $\lambda$ parameters. Because of the preponderance of zero residual water contents (with zero error) produced by the fitting of Eq. (2) it was not possible compare this parameter between shale types. The significance of hysteresis was evaluated using paired ttests on the wetting and drying regime estimates of $\mathrm{P}_{\mathrm{e}}$ and $\lambda$ for all of the shale types for which Eq. (2) converged. Interrelationships between the Brooks and Corey parameters and properties such as matrix density and TOC were explored using linear regression or correlation analyses.

\section{Results and Discussion}

Average values of the matrix density, porosity, and percent mass loss, along with their standard deviations, for all of the shale types are given in Table 1. The results of the TOC measurements can also be found in Table 1 .

ANOVA indicated there were significant differences (at $p<0.05)$ between the shale types in terms of their matrix densities. Based on Tukey's Studentized Range Test, the grey Chattanooga Shale and Mancos Shale had significantly higher matrix densities (2.5 and $2.68 \mathrm{~g}$ $\mathrm{cm}^{-3}$, respectively) than the other shale types, whereas the matrix density of the Barnett Shale $\left(2.26 \mathrm{~g} \mathrm{~cm}^{-3}\right)$ was significantly lower than the other shale types. Since organic carbon has a much lower density than minerals, these results can likely be attributed to differences in TOC. TOC was highest in the Barnett Shale and lowest in the grey Chattanooga Shale and Mancos Shale (Table 1). Overall, there was a very strong inverse linear relationship between mean matrix 
density and TOC (Fig. 3). This relationship has been noted previously and density measurements from well logs have been employed to predict TOC (Kamali and Mirshady, 2004; Vernik and Milovac, 2011; Quirein et al., 2012).

Table 1: Summary of shale properties (average values \pm standard errors).

\begin{tabular}{|l|c|c|c|c|}
\hline \multicolumn{1}{|c|}{$\begin{array}{c}\text { Shale Type } \\
\text { (\# of samples) }\end{array}$} & $\begin{array}{c}\text { Matrix Density } \\
\left(\mathbf{g} / \mathbf{c m}^{\mathbf{3}}\right)\end{array}$ & $\begin{array}{c}\text { Porosity } \\
(\mathbf{v o l . ~ \% )}\end{array}$ & $\begin{array}{c}\text { Mass Loss } \\
(\mathbf{w t .} \%)\end{array}$ & $\begin{array}{c}\text { TOC }^{\dagger} \\
(\mathbf{w t} \text { \% })\end{array}$ \\
\hline Barnett (3) & $2.26 \pm 0.01$ & $13.6 \pm 3.0$ & $0.28 \pm 0.02$ & 13.51 \\
\hline Chattanooga-black (5) & $2.47 \pm 0.002$ & $3.9 \pm 0.6$ & $0.43 \pm 0.05$ & 8.41 \\
\hline Chattanooga-grey (5) & $2.75 \pm 0.01$ & $2.5 \pm 1.2$ & $0.66 \pm 0.18$ & 0.44 \\
\hline Eagle Ford (3) & $2.46 \pm 0.01$ & $12.8 \pm 0.4$ & $0.43 \pm 0.08$ & 5.09 \\
\hline Mancos (4) & $2.68 \pm 0.005$ & $6.3 \pm 1.7$ & $1.15 \pm 0.06$ & 1.32 \\
\hline Marcellus-PA (6) & $2.55 \pm 0.03$ & $8.0 \pm 2.4$ & $0.63 \pm 0.07$ & 8.79 \\
\hline Marcellus-WV (5) & $2.56 \pm 0.02$ & $8.8 \pm 2.5$ & $0.62 \pm 0.07$ & 6.36 \\
\hline
\end{tabular}

Note: \# of samples refers to number of samples used for the density measurements. Mass loss is the percent difference between the oven dry mass before sample wetting and drying, and the oven dry mass after sample wetting and drying. $\dagger \mathrm{TOC}=$ total organic carbon (single measurements with no standard deviations).

For all shale types, except the black Chattanooga and Barnett Shales, the mean values of porosity fell within the reported range of porosities for that shale type (Donnelly, 2015). The Barnett Shale had the greatest porosity (13.6\%), while the grey Chattanooga Shale had the least porosity $(2.5 \%)$. The ANOVA for porosity was significant at $p<0.05$, permitting the null hypothesis, that the different shale types had similar porosities, to be rejected. However, there were large error bars associated with the mean porosity values (Table 1). These uncertainties were likely due to sample heterogeneity and/or the propagation of errors from the separate 
measurements of $\mathrm{V}_{\mathrm{b}}$ and $\mathrm{V}_{\mathrm{s}}$ needed to determine porosity. Because of the large error bars Tukey's Studentized Range Test produced fewer significant differences between the shale types than with matrix density, although the ANOVA was still significant. The mean porosity of each shale type was not significantly different from at least two other shale types. For example, Barnett Shale was not significantly different from the Eagle Ford Shale and WV Marcellus Shale, while grey Chattanooga was not significantly different from black Chattanooga Shale and Mancos Shale.

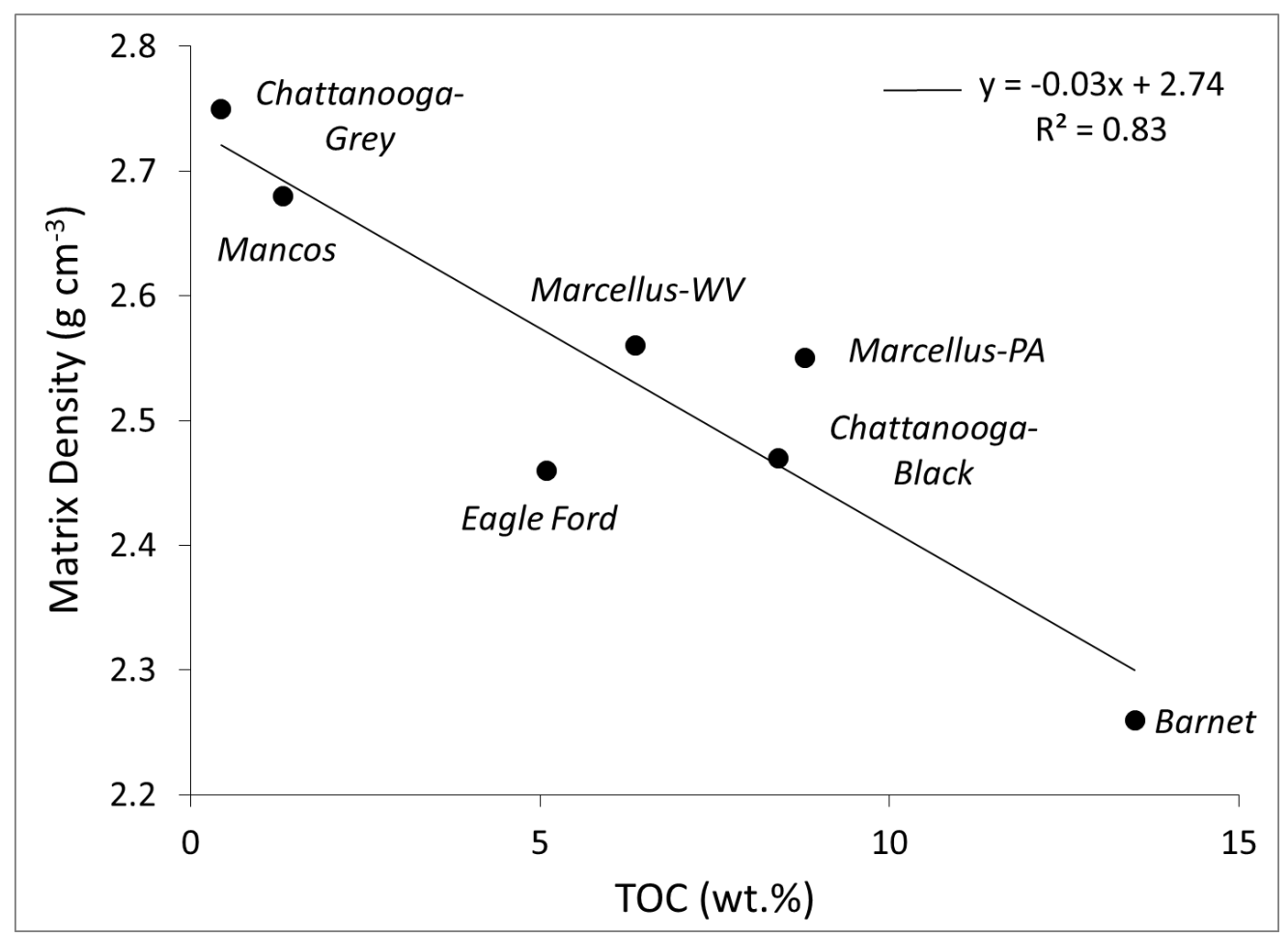

Figure 3. Relationship between matrix density and total organic carbon (TOC) for the 7 shale types investigated.

Oven dry masses were recorded both before wetting and again after saturation and subsequent air drying. All of the shale types experienced some loss of material after this wetting 
/ drying cycle (Table 1). The exact timing and cause of this lost mass is unknown, but it could be due to shale breakage or slaking during the wetting portion of the measurements. Slaking has been shown to occur in shale with density values less than $2.34 \mathrm{~g} \mathrm{~cm}^{-3}$ (Seedsman, 1986). Vapor wetting was employed to prevent slaking, and minimize mass loss. However, four of the six subsamples of Mancos Shale visibly broke apart during vapor wetting. This breakage most likely occurred along bedding planes, as these samples were cut perpendicular to bedding. An earlier study also noted the failure of shale along bedding planes due to air entrapment and pressurization when shale was immersed in water (Schmitt et al., 1994).

Capillary pressure measurements were taken at varying levels of saturation in both the wetting and drying directions. The paired measurements of capillary pressure and volumetric water content for each shale type are plotted in Fig. 4. The error bars in the x-direction are based on the uncertainty of the water activity measurements; they decreased with increasing capillary pressure. It should be noted that data pairs whose capillary pressure measurements were $\leq 1.3$ MPa were not included in Fig. 4 or in the fitting of Eq. (2). This was due to the fact that there was no significant difference between a measurement within this range and a measurement of zero MPa. The error bars in the y-direction are based on the uncertainty of the volumetric water contents. This uncertainty was primarily driven by the error associated with the bulk density determination (see Eq. [7]). As a result, these error bars were independent of capillary pressure or volumetric water content, but varied with shale type. Volumetric water content uncertainty was the greatest for the Barnett Shale, and the least for the Eagle Ford Shale (Fig. 4). 


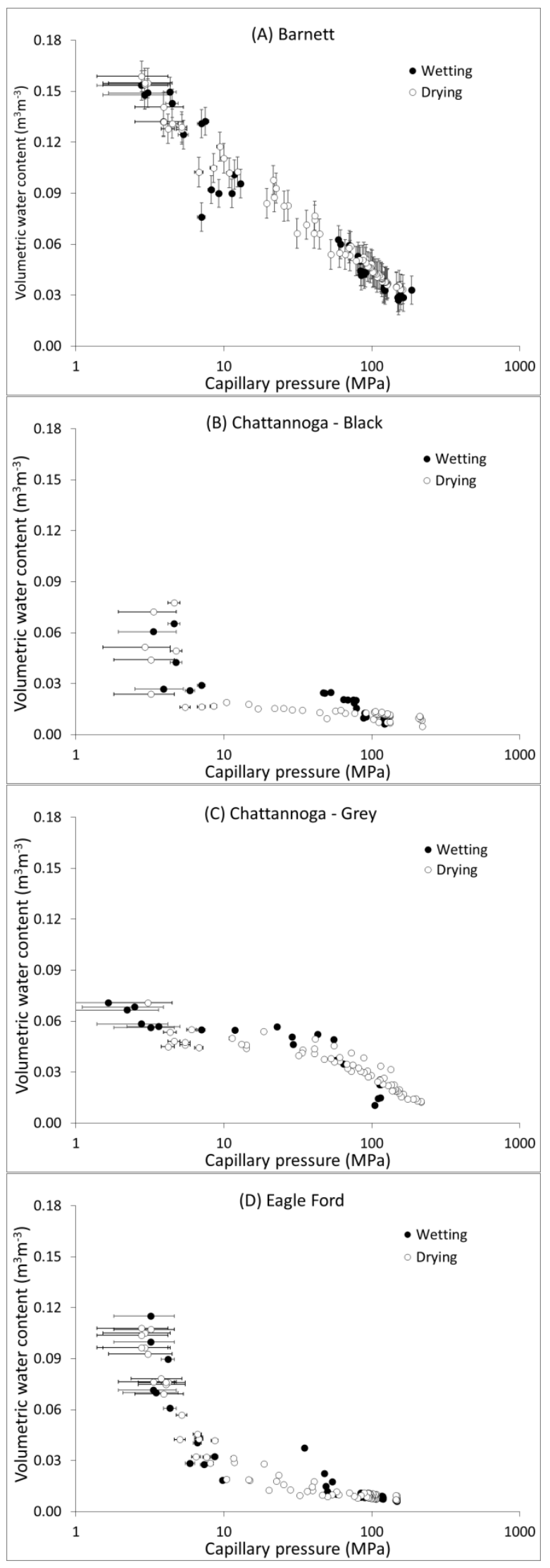

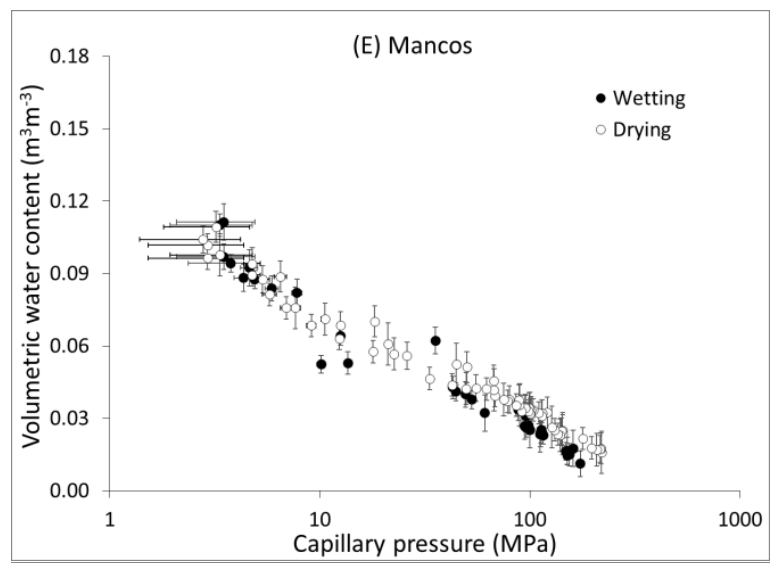
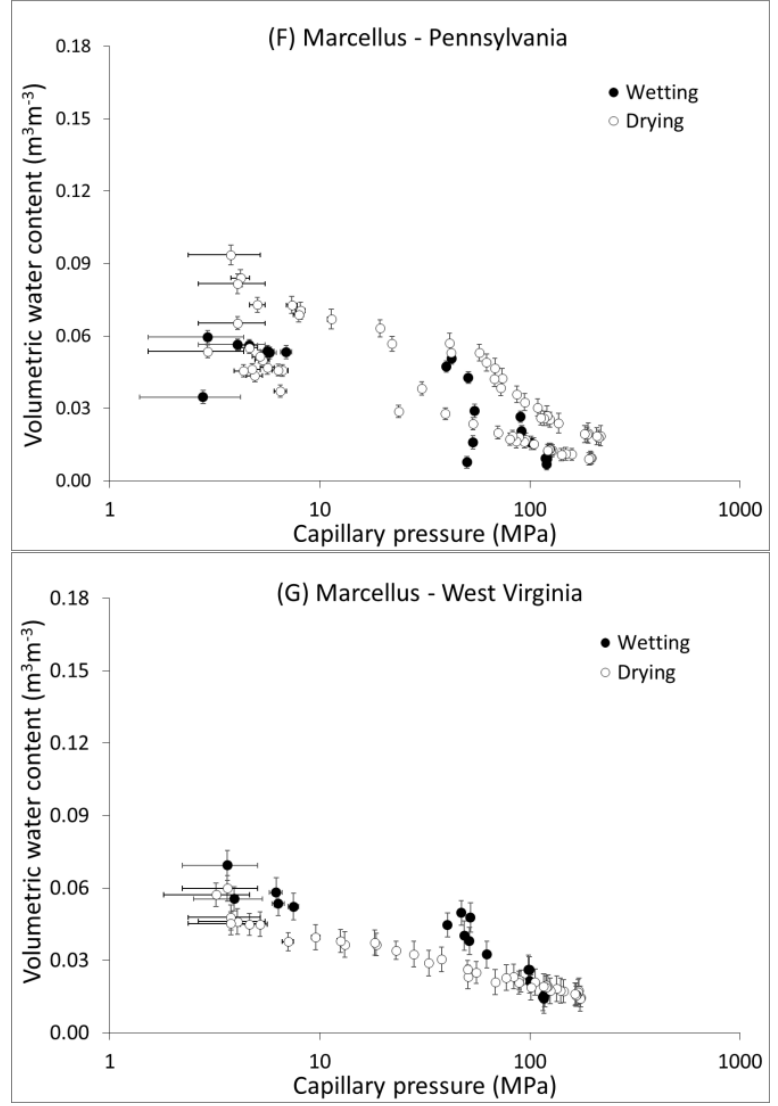

Figure 4. Paired measurements of capillary pressure and saturation (volumetric water content) measured during monotonic wetting and drying for 7 shale types: (A) Barnet, (B) Chattanooga - black, (C) Chattanooga grey, (D) Eagle Ford, (E) Mancos, (F) Marcellus - Pennsylvania, and (G) Marcellus - West Virginia. 
It can be seen in Fig. 4 that the different shale types have different capillary pressure saturation relationships. The maximum volumetric water content values as well as the slopes of the data points appear to be different among the various shales. Further inspection of Fig. 4 also suggests there was little difference between the wetting and drying data sets for any given shale type, indicating negligible hysteresis. Fewer measurements of capillary pressure were obtained while wetting the samples up from oven dryness to saturation than were taken when drying initially-saturated samples (Fig. 4). This was due to differences in the incremental changes in mass achievable with vapor wetting versus air drying. The greatest numbers of data points occur in the low saturation/high capillary pressure range, particularly for the drying measurements (Fig. 4). This trend is important because, as noted previously, shale formations typically have low initial water saturations prior to hydraulic fracturing operations. Combined with the larger uncertainty associated with measuring capillary pressure at high saturations, this means the water activity meter method operates best at the saturations most applicable to gas producing shales.

There appear to be few, if any, alternatives to the water activity meter method for measuring capillary pressures in gas shales. In fact, we are unaware of any previously published capillary pressure - saturation data sets for gas shales. Thus, it was not possible to validate our results against independent measurements obtained using a different method. Mercury intrusion and nitrogen gas adsorption techniques have been employed to characterize shale pore-size distributions (e.g., Kuila and Prasad, 2013), and it is possible to convert such data into capillary pressure - saturation relationships (or vice versa) using Eq. (1). To our knowledge, however, such an analysis has not been published. Thus, a comparative study of measurements obtained from the water activity, mercury intrusion, and/or nitrogen gas adsorption methods may be a potential area for future shale gas research. 
The Brooks and Corey (1964) equation, Eq. (2), was successfully fitted to the wetting and drying capillary pressure - saturation data sets for six of the seven shale types investigated. These fits converged and were significant at $p<0.05$. The goodness of fit, defined as the coefficient of determination $\left(\mathrm{R}^{2}\right)$ between the observed and predicted values, ranged from 0.58 to 0.98 , with a median value of 0.93 (Tables 2 and 3). The non-linear regression analyses for the wetting and drying data sets for the grey Chattanooga Shale did not converge; this was likely due to the convex shape of the data points for this material, as compared to the concave shapes of the other shale types (Fig. 4). This convex shape has been associated with the presence of porebridging clay minerals (Neasham, 1977; Spencer, 1985; Wu and Berg, 2003). X-ray diffraction and scanning electron microscopy could be used in the future to ascertain their occurrence in the grey Chattanooga Shale. It is worth noting that this shale also had the lowest porosity and TOC values of all of the different shale types examined in this study (Table 1).

Half of the successful fits were achieved using the maximum measured porosity instead of the mean measured porosity (Tables 2 and 3). This is because volumetric water contents at low capillary pressures exceeded the mean measured porosity for some of the shale types (Fig. 5). Obviously, this result is physically impossible. The exact source of this discrepancy is unclear, but there are several possible explanations. The first of these, i.e., the presence of external water droplets resulting from condensation or failure to equilibrate, is extremely unlikely since any visible water on sample surfaces was removed with a damp tissue (ChemWipe) prior to analysis. Instead, it is more likely that the discrepancy resulted from sample heterogeneity and loss of solid mass during analysis. The porosity and water activity measurements were made on separate subsamples, and in constructing the capillary pressure saturation relationship all of the subsamples of a particular shale type were pooled. This was 
done to give sufficient data for a robust fit of Eq. (2). However, it necessitated applying a single mean value of porosity to all of the subsamples in the regression analysis. As a result, sample-to-

Table 2: Brooks and Corey parameters (estimated values \pm approximate standard errors) and goodness of fit statistics $\left(\mathrm{R}^{2}\right)$ from segmented non-linear regression analyses for the main wetting branch of the capillary pressure-saturation curve.

\begin{tabular}{|l|c|c|c|c|c|}
\hline $\begin{array}{c}\text { Shale Type } \\
\text { (\# of data pairs) }\end{array}$ & $\begin{array}{c}\boldsymbol{\phi} \\
(\mathbf{v o l .} \%)\end{array}$ & $\begin{array}{c}\boldsymbol{\theta}_{\mathbf{r}} \\
(\mathbf{v o l .} \%)\end{array}$ & $\begin{array}{c}\mathbf{P}_{\mathbf{e}} \\
(\mathbf{M P a})\end{array}$ & $\begin{array}{c}\boldsymbol{\lambda} \\
(-)\end{array}$ & $\begin{array}{c}\mathbf{R}^{2} \\
(-)\end{array}$ \\
\hline Barnett (43) & $16.9^{\dagger}$ & 0 & $2.27 \pm 0.17$ & $0.37 \pm 0.02$ & 0.95 \\
\hline Chattanooga-black (22) & $6.7^{\dagger}$ & 0 & $1.35 \pm 0.52$ & $0.36 \pm 0.06$ & 0.68 \\
\hline Chattanooga-grey (22) & 2.5 & $\mathrm{NA}$ & $\mathrm{NA}$ & $\mathrm{NA}$ & $\mathrm{NA}$ \\
\hline Eagle Ford (36) & 12.8 & $0.010 \pm 0.002$ & $2.61 \pm 0.15$ & $1.54 \pm 0.23$ & 0.91 \\
\hline Mancos (37) & $10.4^{\dagger}$ & 0 & $3.36 \pm 0.22$ & $0.40 \pm 0.02$ & 0.96 \\
\hline Marcellus-PA (20) & 8.0 & 0 & $0.88 \pm 0.54$ & $0.27 \pm 0.06$ & 0.58 \\
\hline Marcellus-WV (18) & 8.8 & 0 & $1.12 \pm 0.50$ & $0.26 \pm 0.04$ & 0.74 \\
\hline
\end{tabular}

Note: \# of data pairs refers to the number of observations included in the regression analyses. $\phi=$ porosity, $\theta_{\mathrm{r}}=$ residual water content, $\mathrm{P}_{\mathrm{e}}=$ water entry pressure, and $\lambda=$ pore-size distribution index. Unless otherwise noted $\phi$ was fixed to the measured average porosity values (given in Table 1). In certain cases improved fits were achieved by fixing $\phi$ to the measured maximum porosity rather than to the mean value; these cases are indicated by the superscripted symbol $\uparrow$. Since the porosity values were not estimated, there are no approximate standard errors. Estimates of $\theta_{\mathrm{r}}=0$ had no associated approximate standard errors because the bounds statement $0 \leq \theta_{\mathrm{r}} \leq \phi$ was included the regression analyses and convergence occurred at the lower boundary of this range in these cases. NA = not applicable (i.e., regression analysis did not converge). 
Table 3: Brooks and Corey parameters (estimated values \pm approximate standard errors) and goodness of fit statistics $\left(\mathrm{R}^{2}\right)$ from segmented non-linear regression analyses for the main drying branch of the capillary pressure-saturation curve.

\begin{tabular}{|l|c|c|c|c|c|}
\hline $\begin{array}{c}\text { Shale Type } \\
\text { (\# of data pairs) }\end{array}$ & $\begin{array}{c}\boldsymbol{\phi} \\
(\mathbf{v o l .} \%)\end{array}$ & $\begin{array}{c}\boldsymbol{\theta}_{\mathbf{r}} \\
(\mathbf{v o l .} \%)\end{array}$ & $\begin{array}{c}\mathbf{P}_{\mathbf{e}} \\
(\mathbf{M P a})\end{array}$ & $\begin{array}{c}\lambda \\
(-)\end{array}$ & $\begin{array}{c}\mathbf{R}^{2} \\
(-)\end{array}$ \\
\hline Barnett (71) & $16.9 \dagger$ & 0 & $2.32 \pm 0.10$ & $0.34 \pm 0.01$ & 0.97 \\
\hline Chattanooga-black (50) & $6.7 \dagger$ & $0.009 \pm 0.002$ & $2.26 \pm 0.36$ & $0.96 \pm 0.28$ & 0.67 \\
\hline Chattanooga-grey (67) & 2.5 & NA & NA & NA & NA \\
\hline Eagle Ford (78) & 12.8 & $0.008 \pm 0.001$ & $2.34 \pm 0.05$ & $1.19 \pm 0.06$ & 0.98 \\
\hline Mancos (64) & $10.4 \dagger$ & 0 & $3.46 \pm 0.22$ & $0.34 \pm 0.01$ & 0.97 \\
\hline Marcellus-PA (70) & 8.0 & 0 & $2.08 \pm 0.45$ & $0.30 \pm 0.03$ & 0.65 \\
\hline Marcellus-WV (45) & 8.8 & 0 & $0.54 \pm 0.07$ & $0.28 \pm 0.01$ & 0.95 \\
\hline
\end{tabular}

Note: \# of data pairs refers to the number of observations included in the regression analyses. $\phi=$ porosity, $\theta_{\mathrm{r}}=$ residual water content, $\mathrm{P}_{\mathrm{e}}=$ air entry pressure, and $\lambda=$ pore-size distribution index. Unless otherwise noted $\phi$ was fixed to the measured average porosity values (given in Table 1). In certain cases improved fits were achieved by fixing $\phi$ to the measured maximum porosity rather than to the mean value; these cases are indicated by the superscripted symbol $\uparrow$. Since the porosity values were not estimated, there are no approximate standard errors. Estimates of $\theta_{\mathrm{r}}=0$ had no associated approximate standard errors because the bounds statement $0 \leq \theta_{\mathrm{r}} \leq \phi$ was included the regression analyses and convergence occurred at the lower boundary of this range in these cases. NA = not applicable (i.e., regression analysis did not converge).

sample variability, combined with slaking-induced mass loss, could explain why some of the volumetric water contents exceeded the mean measured porosity. In these cases (i.e., Barnett, black Chattanooga, and Mancos), the maximum porosity measured for that particular shale type was used in the fitting of Eq. (2) instead of the mean porosity (Fig. 5). 

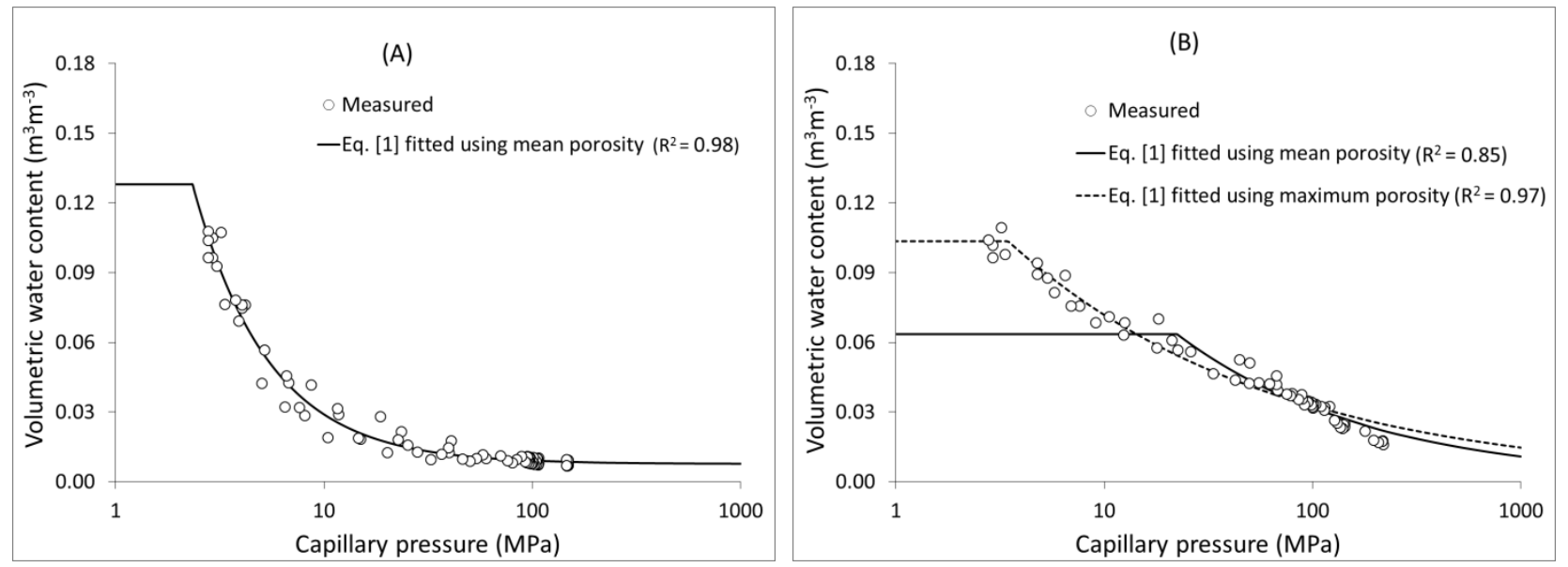

Figure 5. Examples of the Brooks and Corey (1964) equation, Eq. [1], fitted to the experimental data: (A) drying curve data for Eagle Ford showing the best fit relationship based on the mean porosity, and (B) drying curve data for Mancos showing best fit relationships obtained using the mean porosity and maximum porosity, respectively.

Figure 6 shows measured versus predicted water contents during wetting and drying for all of the shale types, except the grey Chattanooga Shale, which could not be fitted with Eq. (2). Despite fewer data points in the wetting direction than in the drying direction, both data sets are very close to an ideal 1:1 relationship, with excellent goodness of fit. The slopes and intercepts of the linear regression analyses indicate there is a slight tendency for the best fits of Eq. (2) to underestimate high water contents and overestimate low water contents. This trend may be related to the unequal distribution of data points within these two regions; most of the points occur at the dry end of the capillary pressure - saturation relationship, where the water activity meter is most accurate, while there are relatively few data at high water contents close to saturation. Thus, these regression results are somewhat biased towards the dry region. However, they indicate the water activity meter method can be used to collect capillary pressure saturation data for a variety of gas shales that can be successfully parameterized with the Brooks and Corey (1964) equation. 

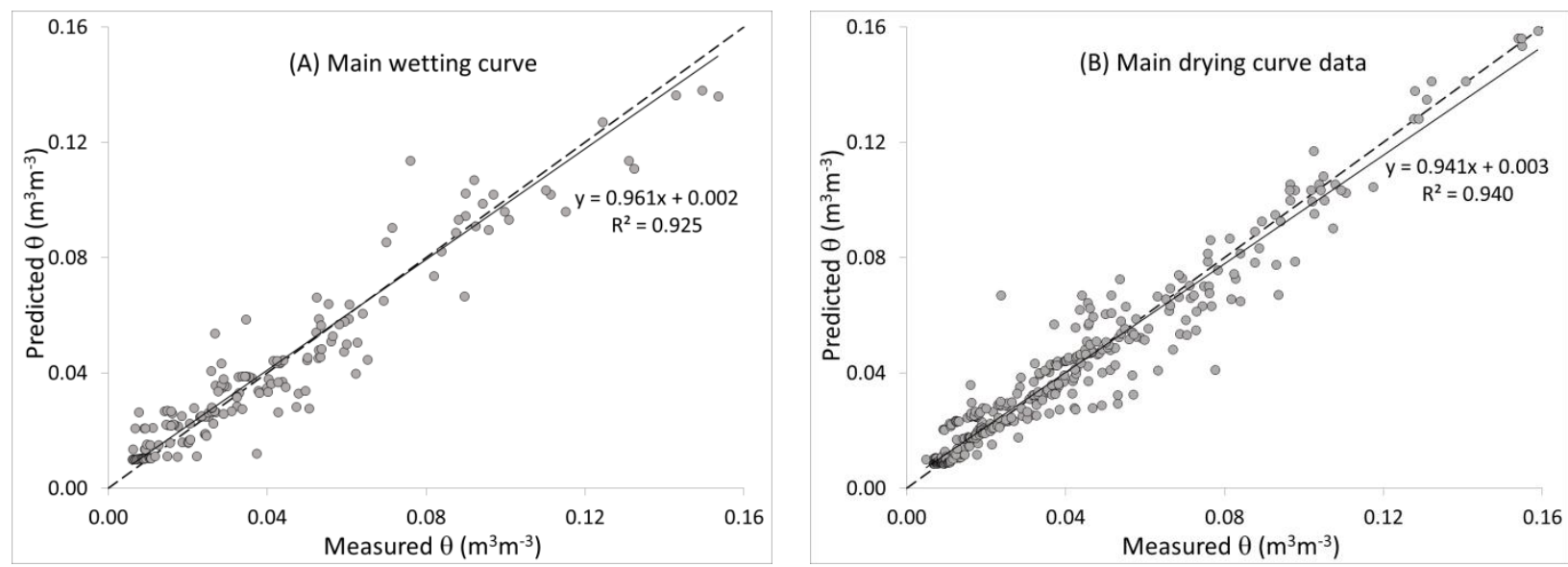

Figure 6. Observed versus predicted volumetric water contents $(\theta)$ for: $(A)$ the main wetting curves and (B) the main drying curves for all of the shale types, except Chattanooga grey (regression analyses for this shale type did not converge successfully). The observed values were measured, while the predicted values were obtained using Eq. [1] in conjunction with the parameters listed in Tables 2 and 3. The solid line is a best fit linear regression model, while the dashed line represents the ideal 1:1 relationship.

Three quarters of the successful fits resulted in estimated residual water contents of zero (i.e., the lower bound in the regression analysis). This was expected as evidence suggests there is no residual water content at high capillary pressure values (Melrose et al., 1994). Since the porosity values were measured, not estimated, and the majority of the $\theta_{\mathrm{r}}$ values were zero, it was only possible to compare the shale types in terms of the $\mathrm{P}_{\mathrm{e}}$ and $\lambda$ Brooks and Corey (1964) parameters. Based on $95 \%$ confidence intervals constructed from the approximate standard errors associated with these parameter estimates in Tables 2 and 3 there were significant differences between the shale types. The Mancos Shale had the highest $\mathrm{P}_{\mathrm{e}}$ parameters, whereas samples from the two Marcellus Shale localities had the lowest values of this parameter, regardless of wetting or drying direction (Tables 2 and 3). Based on Eq. (1) this suggests the largest pores in the Mancos Shale are smaller in size than the largest pores in the Marcellus Shale. In terms of the $\lambda$ 
parameter, the Eagle Ford Shale had the largest values, as compared to the two Marcellus Shale samples, which had the lowest values irrespective of the wetting or drying direction. The larger the $\lambda$ parameter, the steeper the slope of the capillary pressure - saturation curve, and the narrower the pore-size distribution, suggesting Eagle Ford Shale has a relatively narrow range of pore sizes as compared to Marcellus Shale.

Despite differences between the shale types, there were no significant correlations between the $\lambda$ and $\mathrm{P}_{\mathrm{e}}$ capillary pressure - saturation parameters and any of the petrophysical properties measured (i.e., matrix density, porosity, and TOC). This lack of correlation may be related to the sparsity of our data set (only 6 data pairs per wetting/drying cycle since the fits for the grey Chattanooga Shale did not converge successfully). Future studies should expand the number of shale types investigated in order to determine if Brooks and Corey (1964) parameters can be predicted from independent physicochemical properties. Additionally, it would be useful to include additional characterization of the physicochemical properties of the shale types, such as clay mineralogy, specific surface area, and contact angle measurements.

The $\lambda$ and $P_{e}$ parameters from the main wetting and drying branches of the capillary pressure - saturation curves for all of the shale types were positively correlated with each other, although the correlations were only significant at $\mathrm{p}<0.1$. Based on paired t-tests there were no significant differences between the wetting and drying regimes for either parameter. This result indicates that hysteresis may not need to be taken into account in leak off simulations.

A shortcoming of the approach used in the present study was the need to pool data from several subsamples in order to construct a single capillary pressure - saturation relationship for a given shale type. As a result, it was not possible to assess subsample heterogeneity in this relationship, or test for differences in the Brooks and Corey (1964) parameters using ANOVA. 
Because of variations in porosity at the subsample scale, the mean measured porosity value did not always result in the best fit of Eq. (2) to the pooled data. In half of the cases considered, the maximum measured porosity produced better fits than the mean porosity. It would be helpful in future studies of this nature if sufficient wetting and drying data were obtained so that Eq. (2) could be fitted at the subsample scale. This would allow for more accurate parameterization, allow for more robust statistical comparisons, both within and between shale types, and would minimize the impact of experimental error. Also, more controlled methods of wetting and drying need to be developed to minimize mass loss by slaking and produce more data at intermediate saturations. Since the capillary pressure - saturation relationship is known to change with temperature (Bachmann and van der Ploeg, 2002) future water activity meter measurements could also be made at higher temperatures in order to better mimic reservoir conditions.

\section{Conclusions}

Several petrophysical properties were measured for each shale type. Mean porosity values for the different shale types ranged from $2.5 \%$ to $13.6 \%$. Significant differences existed between the different shale types in terms of mean porosity and mean matrix density. TOC was correlated negatively with matrix density; this was expected because organic matter has a much lower density than clay minerals.

The water activity method yielded different air-water capillary pressure - saturation relationships for the different shale types (see Fig. 4); this was expected based on the observed differences in physicochemical properties. We are unaware of any previously published capillary pressure - saturation data sets for gas shales. Thus, it was not possible to validate our results against independent measurements obtained using a different method. 
The Brooks and Corey (1964) equation was fitted to the capillary pressure - saturation measurements using segmented, non-linear regression analysis. All of the wetting / drying data sets were successfully fitted except those for the grey Chattanooga Shale, which had the highest matrix density, lowest porosity, and lowest TOC values. The median $\mathrm{R}^{2}$ value for the successful fits was 0.93. Differences in the Brooks and Corey (1964) entry pressure $\left(\mathrm{P}_{\mathrm{e}}\right)$ and pore-size distribution $(\lambda)$ parameters were found between several of the shale types. However, there were no correlations between these parameters and any of the physicochemical properties investigated. No evidence for hysteresis was found, thus rejecting our hypothesis that the Brooks and Corey (1964) parameters for a given shale type would be different in the wetting and drying directions. Finally, it is worth noting that this study represents an important benchmark for the water activity meter method that has been essentially unused until now for lithified material.

\section{References}

Aguilera, R. 2014. Flow units: From conventional to tight-gas to shale-gas to tight-oil to shaleoil reservoirs. SPE Reserv. Eval. Eng. 17(2): 190-208

Bachmann, J., and R.R. van der Ploeg. 2002. A review on recent developments in soil water retention theory: Interfacial tension and temperature effects. J. Plant Nutr. Soil Sci. 165(4): 468-478

Bradford, S.A., and F.J. Leij. 1996. Predicting two- and three-fluid capillary pressure saturation relationships of porous media with fractional wettability. Water Resour Res, 32(2): 251259

Brooks, R.H., and A. Corey. 1964. Hydraulic properties of porous media. Hydro Paper No. 3. Colorado State University, CO, USA, 37 pp 
Bruner, K.R., and R. Smosna. 2011. A comparative study of the Mississippian Barnett Shale, Fort Worth Basin, and Devonian Marcellus Shale, Appalachian Basin. U.S. Dept. of Energy, 118 pp.

Cancela, J.J., J. Dafonte, E.M. Martínez, T.S. Cuesta, and X.X. Neira. 2006. Assessment of a water activity meter for rapid measurements of soil water potential. Biosyst. Eng. 94(2): $285-295$

Chenevert, M.E. 1970. Shale control with balanced-activity oil-continuous muds. J. Pet. Technol. 22(10): 1309-1316

Christoffersen, K.R., and C.H. Whitson. 1995. Gas/oil capillary pressure of chalk at elevated pressures. SPE Form. Eval. 10(3): 153-159

Clarkson, C., J. Jensen, and T. Blasingame. 2011. Reservoir Engineering for unconventional gas reservoirs: What do we have to consider? Paper SPE 145080. In: SPE North American Unconventional Gas Conference and Exhibition. The Woodlands, Texas, USA, 45 pp.

Dehghanpour, H., H.A. Zubair, A. Chhabra, and A. Ullah. 2012. Liquid intake of organic shales. Energy \& Fuels 26(9): 5750-5758

Donaldson, E.C., N. Ewall, and B. Singh. 1991. Characteristics of capillary pressure curves. J. Pet. Sci. Eng. 6(3): 249-261

Donnelly, B.M. 2015. Measurement of hysteretic shale capillary pressure - saturation relationships using a water activity meter. Unpublished M.S. Thesis, University of Tennessee, Knoxville, TN, USA, 88 pp.

Flint, L.E. 2003. Physical and hydraulic properties of volcanic rocks from Yucca Mountain, Nevada. Water Resour. Res. 39(5): 1-13 
Fredlund, D.G., and A. Xing. 1994. Equations for the soil-water characteristic curve. Can. Geotech. J. 31(3): 521-532

Gao, Z.Y., and Q.H. Hu. 2016. Wettability of Mississippian Barnett Shale samples at different depths: Investigations from directional spontaneous imbibition. AAPG Bull. 100(1): 101114

Gee, G.W., M.D. Campbell, G.S. Campbell, and J.H. Campbell. 1992. Rapid measurement of low soil-water potentials using a water activity meter. Soil Sci. Soc. Am. J. 56(4): 10681070

Glover, L. 1954. Chattanooga Shale investigations along the Sequatchie Anticline of Tennessee and Alabama. U.S. Dept. of the Interior Geological Survey, 38 pp.

Gragg, M.J. 2012. $\mathrm{CO}_{2}$ injection into a deep saline aquifer: porosity measurements, numerical modeling, and costs associated with uncertainty of petrophysical parameters. Unpublished M.Sc. thesis, University of Tennessee, Knoxville, TN, 98 pp.

Green, R.T., G. Rice, and K.A. Meyer-James. 1995. Hydraulic characterization of hydrothermally altered Nopal Tuff. U.S. Nuclear Regulatory Commission, 68 pp.

Holditch, S. 1979. Factors affecting water Blocking and gas flow from hydraulically fractured gas wells. J. Pet. Technol. 31(12): 1515-1524

Jarrett, M.A., B. Gusler, T. Xiang, and D. Clapper. 2004. Improved competence in water activity measurement. Paper AADE-04-DF-HO-31. In: AADE Technical Conference. Houston, Texas, USA, 8 pp.

Josh, M., L. Esteban, C. Delle Piane, J. Sarout, D.N. Dewhurst, and M.B. Clennell. 2012. Laboratory characterisation of shale properties. J. Pet. Sci. Eng. 88-89: 107-124 
Kamali, M.R., and A.A. Mirshady. 2004. Total organic carbon content determined from well $\operatorname{logs}$ using $\Delta$ LogR and Neuro Fuzzy techniques. J. Pet. Sci. Eng. 45(3-4): 141-148

King, G.E. 2012. Hydraulic fracturing 101: What every representative, environmentalist, regulator, reporter, investor, university researcher, neighbor and engineer should know about estimating frac risk and improving frac performance in unconventional gas and oil wells. In: Proceedings of the SPE Hydraulic Fracturing Technology Conference. The Woodlands, Texas, USA, 80 pp.

Kuila, U., and M. Prasad. 2013. Specific surface area and pore-size distribution in clays and shales. Geophys. Prosp. 61: 341-362

Leverett, M.C., and W.B. Lewis. 1941. Steady flow of gas-oil-water mixtures through unconsolidated sands. Trans. AIME 142(1), 107-116

Li, K., and R.N. Horne. 2007. Systematic study of steam-water capillary pressure. Geothermics 36: $558-574$

McLennan, J.D., J.C. Roegiers, and W.P. Marx. 1983. The Mancos Formation: An evaluation of the interaction of geological conditions. In: SPE/DOE Low Permeability Gas Reservoirs Symposium. Society of Petroleum Engineers, Denver, Colorado, USA, 10 pp.

Melrose, J.C. 1987. Use of water vapor desorption data in the determination of capillary pressures. Paper SPE 16286. In: SPE International Symposium on Oilfield Chemistry. San Antonio, Texas, USA, p. 465-475.

Melrose, J.C. 1988. Use of water-vapor desorption data in the determination of capillary pressures at low water saturations. SPE Reserv. Eng. 3(3): 913-918

Melrose, J.C. 1990. Valid capillary pressure data at low wetting-phase saturations. SPE Reserv. Eng. 5(1): 95-99 
Melrose, J.C., J.R. Dixon, and J.E. Mallinson. 1994. Comparison of different techniques for obtaining capillary pressure data in the low-saturation region. SPE Form. Eval. 9(3): $185-192$

Mody, F.K., and A.H. Hale. 1993. Borehole-stability model to couple the mechanics and chemistry of drilling-fluid/shale interactions. J. Pet. Technol. 45(11): 1093-1101

Morrow, N.R., and G. Mason. 2001. Recovery of oil by spontaneous imbibition. Curr. Opin. Colloid Interface Sci. 6(4): 321-337

Mull, C.G. 1995. Preliminary evaluation of the hydrocarbon source rock potential of the Tingmerkpuk Sandstone (Neocomian) and related rocks, northwestern De Long Mountains, Brooks Range, Alaska. State Alaska, Dep. Nat. Resour. Div. Geol. Geophys. Surv., $22 \mathrm{pp}$.

Mullen, J. 2010. Petrophysical characterization of the Eagle Ford Shale in South Texas. In: Canadian Unconventional Resources \& International Petroleum Conference. Society of Petroleum Engineers, Calgary, Alberta, Canada, 19 pp.

Myers, T. 2012. Potential contaminant pathways from hydraulically fractured shale to aquifers. Groundwater 50(6): 872-882

Neasham, J.J.W. 1977. The morphology of dispersed clay in sandstone reservoirs and its effect on sandstone shaliness pore space and fluid flow properties. In: SPE Annual Fall Technical Conference and Exhibition of the Society of Peteroleum Engineers of AIME. Denver, Colorado, USA, 8 pp.

Newsham, K.E., J.A. Rushing, P.M. Lasswell, J.C. Cox, and T.A. Blasingame. 2004. A comparative study of laboratory techniques for measuring capillary pressures in tight gas 
sands. Paper SPE 89866. In: Proceedings of SPE Annual Technical Conference and Exhibition. Society of Petroleum Engineers, Houston, Texas, USA, 11 pp.

Ojeda, G., E. Perfect, J.M. Alcañiz, and O. Ortiz. 2006. Fractal analysis of soil water hysteresis as influenced by sewage sludge application. Geoderma 134(3-4): 386-401

Oleas, A.M., C.E. Osuji, M.E. Chenevert, and M.M. Sharma. 2010. Entrance pressure of oilbased mud into shale: Effect of shale, water activity, and mud properties. SPE Drill. Complet. 25(1): 39-44

Oppenheimer, J.R., A.G. Martin, and L.P. Walker. 1997. Measurements of air-filled porosity in unsaturated organic matrices using a pycnometer. Bioresour. Technol. 59(2-3): 241-247

Perfect, E., A.B. Kenst, M. Díaz-Zorita, and J.H. Grove. 2004. Fractal analysis of soil water desorption data collected on disturbed samples with water activity meters. Soil Sci. Soc. Am. J. 68(4): 1177-1184

Purcell, W.R. 1949. Capillary pressures - their measurement using mercury and the calculation of permeability therefrom. J. Pet. Technol. 1(2): 39-48

Quirein, J., E. Murphy, G. Praznik, J. Witkowsky, S. Shannon, and D. Buller. 2012. A comparison of core and well log data to evaluate porosity, TOC, and hydrocarbon volume in the Eagle Ford Shale. In: SPE Annual Technical Conference and Exhibition. Society of Petroleum Engineers, San Antonio, Texas, USA, 13 pp.

Roen, J.B., and R.C. Kepferle. 1993. Petroleum geology of the Devonian and Mississippian black shale of Eastern North America. U.S. Geological Survey Bulletin 1909, 417 pp.

Rossi, A.M., D.R. Hirmas, R.C. Graham, and P.D. Sternberg. 2008. Bulk density determination by automated three-dimensional laser scanning. Soil Sci. Soc. Am. J. 72(6):1591-1593 
Roychaudhuri, B., T. Tsotsis, and K. Jessen. 2011. An experimental and numerical investigation of spontaneous imbibition in gas shales. Paper SPE 147652. In: Proceedings of SPE Annual Technical Conference and Exhibition. Society of Petroleum Engineers, Denver, Colorado, USA, 11 pp.

Sakhaee-Pour, A., and S.L. Bryant. 2014. Effect of pore structure on the producibility of tightgas sandstones. Am. Assoc. Pet. Geol. Bull. 98(4): 663-69

SAS Institute Inc. 2012. SAS/STAT Version 9.4 Cary, NC, USA. Computer Software.

Schmitt, L., T. Forsans, and F.J. Santarelli. 1994. Shale testing and capillary phenomena. Int. J. Rock Mech. Min. Sci. Geomech. 31(5): 411-427

Schumacher, B.A. 2002. Methods for the determination of total organic carbon (TOC) in soils and sediments. U.S. Environ. Prot. Agency, 25 pp.

Seedsman, R. 1986. The behaviour of clay shales in water. Can. Geotech. J. 23(1): 18-22

Selley, R.C. 1985. Elements of Petroleum Geology. First Ed. W. H. Freeman and Company

Shang, S., R.N. Horne, and H.J. Ramey. 1995. Water vapor adsorption on geothermal reservoir rocks. Geothermics 24(4): 523-540

Shikhov, I., and C.H. Arns. 2015. Evaluation of capillary pressure methods via digital rock simulations. Transp. Porous Media 107(2): 623-640

Skinner, L.M., and J.R. Sambles. 1972. The Kelvin equation - A review. J. Aerosol Sci. 3(3): $199-210$

Slobod, R.L., A. Chambers, and W.L. Prehn Jr. 1951. Use of centrifuge for determining connate water, residual oil, and capillary pressure curves of small core samples. J. Pet. Technol. 3(4): 127-134 
Spencer, C.W. 1985. Geologic aspects of tight gas reservoirs in the Rocky Mountain region. J. Pet. Technol. 37(7): 1308-1314

Stevens, S., and V. Ruuskraa. 2009. Special report: Gas shale-1: Seven plays dominate North America activity. Oil Gas J.: 36-41

Takahashi, S., and A.R. Kovscek. 2010. Spontaneous countercurrent imbibition and forced displacement characteristics of low-permeability, siliceous shale rocks. J. Pet. Sci. Eng. 71(1-2): 47-55

Thomson, W. (Lord Kelvin) 1872. On the Equilibrium of Vapour at a Curved Surface of Liquid. Proc. R. Soc. Edinburgh 7: 63-68

U.S. Energy Information Administration. 2011. Review of emerging resources: U.S. shale gas and shale oil plays. Washington D.C., 105 pp.

Vavra, C.L., J.G. Kaldi, and R.M. Sneider. 1992. Geological applications of capillary pressure: a review. AAPG Bull. 76(6): 840-850

Vernik, L., and J. Milovac. 2011. Rock physics of organic shales. Lead. Edge 30(3): 318-323

Wang, D.M., R. Butler, H. Liu, and S. Ahmed. 2011. Flow rate behavior and imbibition in shale. SPE Res. Eval. Eng. 14(4): 505-512

Wu, T., and R.R. Berg. 2003. Relationship of reservoir properties for shaly sandstones based on effective porosity. Petrophysics 44(5): 328-341

Zhang, J., J. Rojas, and D. Clark. 2008. Stressed-shale drilling strategy: Water-activity design improves drilling performance. Paper SPE 102498. SPE Drill. Complet. 23(4): 385-393

Zhuang, J., J.F. McCarthy, E. Perfect, L.M. Mayer, and J.D. Jastrow. 2008. Soil water hysteresis in water-stable microaggregates as affected by organic Matter. Soil Sci. Soc. Am. J. 72(1): $212-220$ 